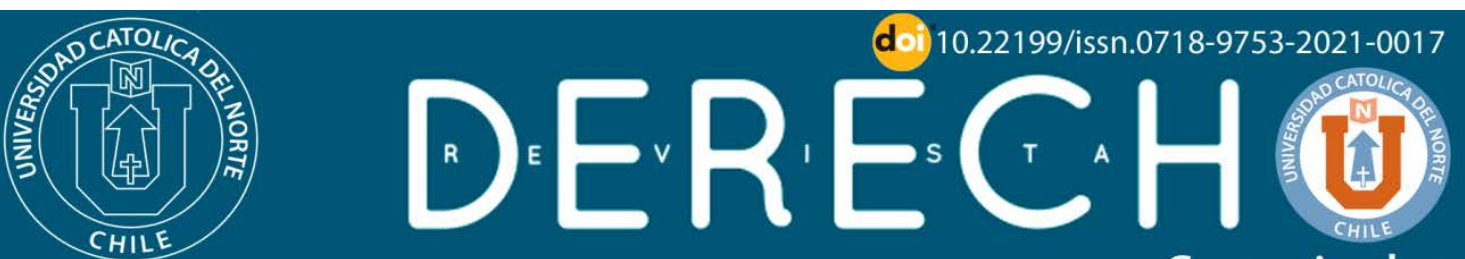

Co qui m bo

REVISTAS CIENTIFICAS

ISSN: 0718-9753 (En línea)

\title{
Amnistías fiscales en Chile: un análisis desde los principios Constitucionales de igualdad y legalidad tributarias
}

\section{Tax amnesties in Chile: a Constitutional analysis in terms of legality and tax equity}

\author{
Patricia Toledo Zúñiga' (i) https://orcid.org/0000-0002-0438-6348 \\ Felipe Ignacio Paredes Paredes² (1D https://orcid.org/0000-0003-0232-1919
}

\begin{abstract}
'Universidad Austral de Chile, Valdivia, Chile. Facultad de Ciencias Jurídicas y Sociales. Profesora de Derecho Tributario Abogada. Doctora en Derecho, U. Pompeu Fabra. patricia.toledo@uach.cl ${ }^{2}$ Universidad Austral de Chile, Valdivia, Chile. Facultad de Ciencias Jurídicas y Sociales. Profesor de Derecho Constitucional. Abogado. Doctor en Derecho, U Pompeu Fabra. felipe.paredes@uach.cl
\end{abstract}

(cc) BY

\section{Resumen:}

En las últimas décadas en Chile se han promovido medidas que pueden calificarse como "amnistías fiscales", cuya finalidad es aumentar los ingresos públicos. En este sentido, encontramos amnistías fiscales permanentes, como la política de condonación de intereses y multas generadas por el cumplimiento moroso de una obligación tributaria y otras de carácter transitoria, como la repatriación de capitales, incorporada por la Ley $N^{\circ} 20.780$. Se analizan ambos tipos de medidas, argumentando razones de constitucionalidad para concluir que estas deben ocupar un lugar muy excepcional en el sistema tributario. Concretamente, el artículo plantea que este tipo de medidas podría colisionar con el principio constitucional de igualdad tributaria, tanto en su sentido horizontal como vertical, así como con el principio constitucional de legalidad tributaria.

Palabras Clave: Condonación de impuestos; Principio de igualdad tributaria; Principio de legalidad tributaria.

\begin{abstract}
:
In the last decade, several tax amnesties policies have been established in Chile in order to increase public revenues. In this sense, distinguish between permanent and temporary tax amnesties policies is needed. On the one hand, it is possible to exemplify the forgiveness policy of interests and fines caused by delayed accomplishments of tax obligations. On the other hand, we can mention some repatriation of capital programs, especially those set by Law No. 20.780. Both types of policies are analyzed, describing a tenseness between those policies and the Chilean Constitution. Specifical$l y$, the article states that such measures could collide with the constitutional principle of tax equity, both horizontally and vertically, as well as with the constitutional principle of tax legality. In the same vein, the paper to conclude that tax amnesties should play an exceptional role in the tax system.

Keywords: Tax amnesty; Tax equity; Tax legality
\end{abstract}


Amnistías fiscales en Chile: un análisis desde los principios Constitucionales de igualdad...

\section{Introducción}

La cuestión impositiva, representa un asunto de suma importancia para cualquier gobierno, pues en ese terreno se juega parte muy importante del financiamiento de su programa político. Desde esta perspectiva, las denominadas amnistías fiscales representan una tentación grande de obtener réditos en el corto plazo. Sin embargo, si estas no se diseñan adecuadamente, pueden ocasionar perniciosas consecuencias.

Existen dos tipos de razones que permiten explicar la utilización de las amnistías fiscales: las económicas y las políticas. En primer lugar, estas medidas permiten inyectar rápidamente recursos con los que el fisco no contaba; estos ingresos adicionales pueden ser más deseables en tiempos de recesión o cuando sea necesario aumentar el gasto público. En segundo lugar, a pesar de que cumplen un importante papel en la redistribución del ingreso, los impuestos no suelen ser populares entre los contribuyentes. Por ello, las amnistías fiscales pueden ser utilizadas para transmitir un mensaje político de flexibilidad en materia tributaria, concitando el respaldo de aquellos sectores partidarios de una política tributaria menos gravosa.

Si bien las amnistías tributarias son un instrumento utilizado en muchos sistemas tributarios, la tesis que plantea este trabajo es que estas medidas generalmente entran en tensión con las normas constitucionales que establecen los principios básicos sobre justicia tributaria; por tanto, deben ser diseñadas con cautela. Esta tensión puede producirse tanto a nivel legislativo como administrativo. En Chile, esta institución se ha utilizado sin considerar los problemas de constitucionalidad antes señalados, lo que obliga a una revisión de su diseño e implementación.

Con el objeto de discutir la tesis mencionada, se seguirá la siguiente estructura: En la sección 1, se analizan algunos conceptos básicos sobre la obligación tributaria y los efectos jurídicos de su cumplimiento moroso. En la sección 2, se conceptualizan las amnistías fiscales, cotejando sus ventajas y desventajas. Asimismo, se presentan dos ejemplos de amnistías fiscales en Chile: la condonación de intereses y multas generadas por el cumplimiento moroso de una obligación tributaria, como un caso de amnistía fiscal permanente, y la repatriación de capitales incorporada por la Ley $N^{\circ} 20.780$ (2014), como ejemplo de amnistía fiscal transitoria. En la sección 3, se analiza cómo ambas medidas de amnistía fiscal pueden lesionar el principio constitucional de igualdad tributaria, en sentido horizontal y en sentido vertical. En la sección 4, se argumenta que ambas medidas de amnistía fiscal son susceptibles de colisionar con el principio constitucional de legalidad tributaria. Se finaliza con la formulación de las conclusiones. 


\section{Obligación tributaria y efectos jurídicos de su cumplimiento mo- roso}

De acuerdo con la Constitución Política de la República de Chile (2005),

El Estado está al servicio de la persona humana y su finalidad es promover el bien común, para lo cual debe contribuir a crear las condiciones sociales que permitan a todos y a cada uno de los integrantes de la comunidad nacional su mayor realización espiritual y material posible... (art. 1, inc. 4)

Es evidente que la actividad estatal necesita ser financiada. Los ingresos con los que el Estado financia sus gastos, pueden provenir de su actividad económica patrimonial o del ejercicio de sus potestades sancionatoria y tributaria. Siguiendo a Giuliani Fonrouge (1970), se puede definir la potestad tributaria como "la facultad o la posibilidad jurídica del Estado, de exigir contribuciones con respecto a personas o bienes que se hallan en su jurisdicción" (p. 279).

Dada su importancia, normalmente son las propias Constituciones las que establecen las bases del sistema tributario, consagrando, por ejemplo, el deber de contribuir o los principios esenciales de justicia tributaria. En Chile, el deber de contribuir al sostenimiento de los gastos públicos se encuentra implícito en la Constitución Política de la República de Chile (2005), que establece "La igual repartición de los tributos en proporción a las rentas o en la progresión o forma que fije la ley...". (art. 19, no. 20, inc. 1). Con todo, sea que el deber de contribuir se haya establecido constitucionalmente de manera explícita o de manera implícita, siempre es el legislador quien, en ejercicio de su facultad constitucional -véase Constitución Política de la República de Chile, 2005, arts. 19, no. 20; art. 65 inc. $4^{\circ}$ en relación con el art. 63, no. 14-, debe establecer y regular en forma específica la obligación de pagar tributos.

Como consecuencia de dicha atribución, entre el Estado y el contribuyente existe una relación jurídico-tributaria que surge en el momento en que la conducta del contribuyente configura el hecho imponible regulado por la ley. Esta relación jurídico-tributaria, consiste en un conjunto de derechos y obligaciones que vinculan -como sujeto activo- al Estado y -como sujeto pasivo- al contribuyente. En la relación jurídico-tributaria se pueden distinguir una obligación principal y una serie de obligaciones accesorias. La obligación principal consiste en un vínculo jurídico en virtud del cual un sujeto -generalmente el contribuyente- debe dar al Estado, sumas de dinero determinadas por ley; a esta obligación principal también se le denomina "obligación tributaria". Las obligaciones accesorias están conformadas por una serie de obligaciones jurídicas que vinculan al Estado con un sujeto pasivo -generalmente el contribuyente- y que tienen por finalidad asegurar el cumplimiento cabal y oportuno del pago de tributos; estas obligaciones tributarias accesorias también se denominan "deberes tributarios". 
El objeto de la obligación tributaria es el pago de los tributos. Los tributos se suelen clasificar en impuestos, tasas y contribuciones. Los impuestos constituyen la principal fuente de ingresos del Estado. Por una parte, los impuestos son el tipo de tributo que más recauda; por otra, los ingresos tributarios representan estadísticamente la principal fuente de ingresos estatales. En la última década, los ingresos netos tributarios constituyen más del $70 \%$ de los ingresos totales del Estado y su incidencia ha ido en aumento. Para ilustrar la importancia significativa que tienen los ingresos tributarios para el Estado, considérese que las "Estadísticas de las Finanzas Públicas 2007-2016" (Ministerio de Hacienda de Chile, 2017, pp. 78-81) permiten concluir que el año 2007 los ingresos tributarios netos constituyeron el 69,99\% de los ingresos totales; el año 2010, los ingresos tributarios netos constituyeron el $73,61 \%$ de los ingresos totales; el año 2013, los ingresos tributarios netos constituyeron el $79,60 \%$ de los ingresos totales; el año 2016 , los ingresos tributarios netos constituyeron el $82,36 \%$ de los ingresos totales

El cumplimiento de la obligación tributaria, dada su importancia, se encuentra protegido jurídicamente. En este sentido, el contribuyente que no cumple completa y oportunamente con la obligación de pagar impuestos debe pagar su obligación reajustada, y es sancionado con el pago de intereses y multas.

De acuerdo con el Código Tributario (Decreto Ley $\left.N^{\circ} 830,1974\right)$, que señala que:

Todo impuesto o contribución que no se pague dentro del plazo legal se reajustará en el mismo porcentaje de aumento que haya experimentado el índice de precios al consumidor en el período comprendido entre el último día del segundo mes que precede al de su vencimiento y el último día del segundo mes que precede al de su pago. (art. 53, inc. 1)

El reajuste establecido, corresponde a la variación que experimente el índice de precios al consumidor (IPC) entre la fecha de vencimiento de la obligación tributaria y la fecha en que se realizó su pago. Como destaca Massone Parodi (2016, p. 1950), la aplicación del reajuste es una mera actualización del valor de lo debido considerando los efectos de la inflación; por tanto, la aplicación del reajuste no debe ser calificada como una sanción (Carvalho, 1997, p. 338), carácter que sí presentan los intereses y multas.

El interés establecido es del 1,5\% por cada mes o fracción de mes de retraso, aplicado sobre la deuda reajustada.

El contribuyente estará afecto, además, a un interés penal del uno y medio por ciento mensual por cada mes o fracción de mes, en caso de mora en el pago del todo o de la parte que adeudare de cualquier clase de impuestos y contribuciones. Este interés se calculará sobre los valores reajustados en la forma señalada en el inciso primero. (Decreto Ley $\mathrm{N}^{\circ} 830$, 1974 , art. 53, inc. 3) 
Nótese que la tasa de interés establecida es altísima, siendo equivalente a una tasa anual del $18 \%$, muy superior al interés máximo convencional que fija la Superintendencia de Bancos e Instituciones Financieras (Pérez Rodrigo, 2017, p. 180). Las multas aplicables son del 10\%, aumentable, dependiendo de si se trata de un impuesto sujeto o no a retención o recargo.

Tratándose de impuestos no sujetos a retención o recargo, rige lo dispuesto Código Tributario

Las siguientes infracciones a las disposiciones tributarias serán sancionadas en la forma que a continuación se indica:

[...]

$2^{\circ}$.- El retardo u omisión en la presentación de declaraciones o informes, que constituyan la base inmediata para la determinación o liquidación de un impuesto, con multa de diez por ciento de los impuestos que resulten de la liquidación, siempre que dicho retardo u omisión no sea superior a 5 meses. Pasado este plazo, la multa indicada se aumentará en un dos por ciento por cada mes o fracción de mes de retardo, no pudiendo exceder el total de ella del treinta por ciento de los impuestos adeudados. (Decreto Ley $\mathrm{N}^{\circ} 830,1974$, art. 97 , no. 2, inc. 1)

Tratándose de impuestos sujetos a retención o recargo rige lo dispuesto:

$11^{\circ}$.- El retardo en enterar en Tesorería impuestos sujetos a retención o recargo, con multa de un diez por ciento de los impuestos adeudados. La multa indicada se aumentará en un dos por ciento por cada mes o fracción de mes de retardo, no pudiendo exceder el total de ella del treinta por ciento de los impuestos adeudados.

En los casos en que la omisión de la declaración en todo o en parte de los impuestos que se encuentren retenidos o recargados haya sido detectada por el Servicio en procesos de fiscalización, la multa prevista en este número y su límite máximo, serán de veinte y sesenta por ciento, respectivamente. (Decreto Ley Nº 830, 1974, art. 97, no. 11)

La fijación de intereses altos responde a la necesidad de desincentivar que los contribuyentes dejen de pagar sus impuestos oportunamente, invirtiendo el dinero en otras actividades económicas, pues de esta forma se evita que resulte económicamente rentable el cumplimiento tardío de la obligación tributaria. El establecimiento de multas, tiene por objetivo que los contribuyentes perciban que el incumplimiento de las obligaciones tributarias conlleva la imposición de una sanción.

Es importante destacar el carácter sancionatorio de los intereses y las multas; especialmente, por su rol disuasorio. La sanción, es uno de los conceptos básicos de la teoría del Derecho. Según Kelsen (1982) estas consisten en "irrogar coactivamente un mal, o expresado negativamente, en la privación de un bien" (p. 123). Para Nino 
Amnistías fiscales en Chile: un análisis desde los principios Constitucionales de igualdad...

(2003), el concepto de sanción kelseniano puede configurarse a partir de los siguientes elementos:

a) se trata de un acto coercitivo, o sea de un acto de fuerza efectiva o latente; b) tiene por objeto la privación de un bien; c) quien lo ejerce debe estar autorizado por una norma válida; $y \mathrm{~d}$ ) debe ser la consecuencia de una conducta de algún individuo. (p. 123)

El carácter sancionatorio de los intereses y las multas ha sido reconocido por la jurisprudencia constitucional, al resolver que:

...el interés fijado por el susodicho artículo 53 podría encontrar su razón de ser en la necesidad de asegurar el pronto pago de los tributos que se adeudan al fisco. Esto es, en impedir que los contribuyentes prioricen el cumplimiento de otras deudas en desmedro de aquellas que se tienen con el Estado. (Requerimiento de inaplicabilidad por inconstitucionalidad. Ilustre Municipalidad de Maipú con Servicio de Impuestos Internos, 2018, cons. segundo)

Esta sentencia es muy importante porque con ella el Tribunal Constitucional cambia su jurisprudencia anterior, que establecía que los intereses del Decreto Ley $\mathrm{N}^{\circ}$ 830 (1974, art. 53) no poseen un carácter sancionatorio, sino que más bien representan una avaluación anticipada de los perjuicios fiscales, cumpliendo una función análoga a la cláusula penal en materia civil (véase las sentencias; Declaración de inaplicabilidad por inconstitucionalidad. Comercial Único Limitada con Servicio de Impuestos Internos, 2014; Declaración de inaplicabilidad por inconstitucionalidad. AFP Santa María con Club de Deportes Santiago Wanderers, 2014; y Declaración de inaplicabilidad por inconstitucionalidad. AFP Provida con Club de Deportes Santiago Wanderers, 2014). El mismo razonamiento de la mencionada sentencia Rol No 3440-17 (Requerimiento de inaplicabilidad por inconstitucionalidad. Ilustre Municipalidad de Maipú con Servicio de Impuestos Internos, 2018), puede ser aplicado a fortiori para el caso de las multas.

Para comprender cabalmente la importancia de la finalidad disuasoria de los intereses y multas es necesario tener presente que, a diferencia de la obligación civil, en materia tributaria es el sujeto pasivo quien debe determinar si existe o no una obligación tributaria. En caso de que esta exista, es el mismo sujeto pasivo quien debe determinar cuál es el contenido de la obligación tributaria que debe cumplir. Esta característica se denomina principio de autodeterminación del impuesto. Por su parte, la entidad administrativa ve limitada su función de fiscalización de la labor realizada por el sujeto pasivo de la obligación tributaria y, para este efecto, la información que le proporcionan este $u$ otros sujetos por medio del cumplimiento de las obligaciones tributarias accesorias, resulta fundamental. 


\section{Amnistías fiscales: concepto y dos ejemplos chilenos}

Según la clásica definición de Lerman (1986), se denomina amnistía fiscal a:

Under a tax amnesty, civil and criminal penalties are waived for taxpayers or for those who should have been taxpayers who voluntarily admit that they have not paid the corret amount of tax for some prior period and who pay the full amount of their unpaid tax ${ }^{1}$.(p. 325)

La amnistía fiscal, constituye una excepción a la aplicación de la teoría de la obligación tributaria y los efectos jurídicos de su incumplimiento, no obstante, no es extraño que los Estados recurran a políticas de este tipo. Así lo ponen en evidencia López Laborda y Rodrigo Sauco (2002), quienes identificaron amnistías fiscales concedidas en países de Europa, América, Asia y Oceanía.

De acuerdo con Alm (1998), en el diseño de una amnistía fiscal es necesario considerar cuatro elementos básicos. Primero, la elegibilidad, esto es, distinguir cuáles son los contribuyentes que pueden acogerse a la amnistía fiscal. Segundo, la cobertura, esto es, determinar cuáles son los impuestos incluidos en la amnistía fiscal. Tercero, los incentivos, es decir, cuáles son los beneficios que se ofrecen a quienes se acojan a la amnistía fiscal. Cuarto, la duración, es decir, cuál es el período de duración de la amnistía fiscal. En este sentido, se distingue entre amnistías fiscales permanentes y amnistías fiscales transitorias.

Dentro de las buenas razones que motivan a las administraciones tributarias a implementar amnistías fiscales, destacan las tres siguientes:

a) Las amnistías fiscales son soluciones eficientes para mejorar la recaudación a corto plazo. Esto cobra especial relevancia en épocas de crisis económicas porque, como destaca Álvarez García (2012), aparecen como una alternativa menos impopular "...entre los contribuyentes, como el recorte en los gastos públicos o la subida de impuestos" (p. 9).

b) Las amnistías fiscales permiten incrementar las listas de contribuyentes de un Estado. En efecto, al fomentar la regularización de contribuyentes que no estaban cumpliendo con sus obligaciones tributarias, mejoran las bases de datos de las administraciones tributarias y facilitan el control futuro de estos contribuyentes.

c) Las amnistías fiscales, resultan idóneas para facilitar la transición a nuevos regímenes de tributación. Reformas tributarias sustantivas pueden verse facilitadas con la implementación de amnistías fiscales transitorias.

\footnotetext{
1 "Una medida o conjunto de medidas, que tiene por objeto condonar penas o sanciones de carácter civil y criminal a los contribuyentes que admitan voluntariamente no haber pagado la obligación tributaria correspondiente a impuestos de períodos precedentes, o haberlo hecho parcialmente, y que ahora declaran por entero". Traducción de los autores
} 
Con todo, las amnistías fiscales también presentan costes y efectos negativos, dentro de los cuales cabe considerar los siguientes:

a) Las amnistías fiscales pueden disminuir la recaudación a largo plazo. Dado el estrecho vínculo entre las amnistías fiscales y la evasión fiscal, la cuestión es determinar si este tipo de medidas representa un paliativo o un agravamiento del fenómeno. Para profundizar, ver, Stella (1991).

Existe poca claridad sobre los efectos económicos de las amnistías fiscales a largo plazo. Así, por ejemplo, en Estados Unidos se produjo un gran debate en la década de 1980, no alcanzándose un consenso al respecto. Mientras Jackson (1986) elogia la experiencia de algunos estados, en contraste, Lerman (1986), enfatiza los riesgos potenciales y minimiza el tamaño de la posible ganancia de ingresos para el Gobierno Federal.

En términos generales, López Laborda y Rodrigo Sauco (2002) sistematizan los resultados logrados por los modelos teóricos y desarrollo empíricos de análisis económico. Destacan que la literatura que se ha preocupado por la estimación de los efectos en el largo plazo, no ha resuelto todavía la incógnita acerca del impacto final de estos instrumentos tributarios y, muy por el contrario, ha servido unas veces para mostrar la eficacia de las amnistías en la lucha contra el fraude, otras su inocuidad y otras su contribución negativa. Las amnistías fiscales, implican un reconocimiento de la administración tributaria de estar realizando una fiscalización deficiente. Incluso, autores como Barrachina Juan, consideran "...la amnistía fiscal puede ser considerada sinónimo de fracaso en la política económica y las medidas que se adoptaron contra el fraude" (citado en Armentia Basterra, 2015, p. 80).

Evidentemente, como destaca Álvarez García (2012), la percepción de debilidad de la administración tributaria "...se ve amplificado si se generan expectativas de que van a producirse nuevas amnistías en el futuro" (p. 9).

b) Las amnistías fiscales, pueden desincentivar el cumplimiento futuro de los contribuyentes honestos. En efecto, las amnistías fiscales pueden ser percibidas como injustas porque tratan mejor a los contribuyentes incumplidores en relación con los contribuyentes cumplidores.

En este mismo sentido, la OCDE ha recalcado que, si bien pueden ser consideradas una herramienta válida, las amnistías fiscales se sitúan en un delicado equilibrio que debe tener en cuenta la ponderación de dos objetivos. Por una parte, que los contribuyentes incumplidores regularicen su situación, pero, como contrapartida, que ello no represente un incentivo para el incumplimiento sistemático en el futuro. Por tanto, las amnistías fiscales deberían insertarse siempre en el marco de una estrategia general de cumplimiento regular de las obligaciones tributarias (Organisation for Economic Co-operation and Development [OCDE], 2015). 
Ahora bien, la discusión sobre las condonaciones tributarias no solamente posee una importancia económica, sino que también reviste una dimensión constitucional. Así, por ejemplo, Patón García (2013) en el caso de España, señala que la articulación de técnicas convencionales entre la administración y el contribuyente debe subordinarse a los principios constitucionales de legalidad, indisponibilidad de la obligación tributaria, capacidad económica, igualdad y eficiencia. Esta discusión, también se ha producido en Alemania. Kellner (2004) plantea el problema a propósito de la amnistía fiscal de 2004, arguyendo que las amnistías implican que quienes no pagan oportunamente son tratados de mejor forma que los que pagan oportuna y correctamente, lo que puede estar en pugna con el derecho fundamental a la igualdad reconocido en el artículo 3.1. de la Constitución alemana. De todas formas, la ley alemana en comento logró pasar el filtro de la constitucionalidad; por el contrario, el Real Decreto-Ley 12/2012 español fue declarado inconstitucional. La sentencia del Tribunal Constitucional de España 73/2017, señala que las condonaciones inciden directa y sustancialmente en la determinación de la carga tributaria que afecta a los contribuyentes; concluye que

...con esta medida normativa se ha afectado a la esencia misma del deber de contribuir al sostenimiento de los gastos públicos que enuncia el art. 31.1 CE, al haberse alterado el modo de reparto de la carga tributaria que debe levantar la generalidad de los contribuyentes, en unos términos que resultan prohibidos por el art. 86.1 CE. (Recurso de inconstitucionalidad. Diputados del Grupo Parlamentario Socialista en el Congreso de los Diputados contra la disposición adicional primera del Real Decreto-Ley 12/2012, de 30 de marzo, 2017, fj. 4, inc. 4)

Considerando lo expuesto, especialmente lo señalado por la doctrina comparada, proponemos un modelo mínimo de cuatro criterios básicos que deberían respetarse al momento de diseñar e implementar amnistías fiscales:

a) Excepcionalidad en la elegibilidad. Las amnistías fiscales deberían aplicarse solo a contribuyentes que, encontrándose en morosidad, no presenten incumplimientos dolosos o culpables. De este modo, se busca evitar que las amnistías fiscales sean percibidas como un premio al contribuyente evasor de la ley tributaria.

b) Desincentivo de la reincidencia. Por razones similares al criterio anterior, las amnistías fiscales deberían aplicarse solo a contribuyentes que no sean reincidentes. En sentido similar, la OCDE sugiere que la persistencia en el incumplimiento debe ser causa de una disminución de las posibilidades para optar a un programa de estas características (OCDE, 2015).

c) Prohibición de premio al incumplimiento. Las amnistías fiscales, deben establecerse de manera que nunca el contribuyente moroso reciba un tratamiento tributario más beneficioso que el contribuyente que cumple oportunamente. Esto es importante porque, de lo contrario, se emite un mensaje en el sen- 
tido de que la evasión es tolerable e insignificante; pudiendo generar graves consecuencias financieras a largo plazo al reducirse el cumplimiento tributario oportuno y voluntario.

d) Principio de reserva legal. Como consecuencia del principio constitucional de legalidad tributaria, los aspectos básicos de las amnistías fiscales deben estar establecidos por ley, dejando solo los aspectos de detalle a la normativa de carácter administrativo.

\subsection{Amnistía fiscal permanente en Chile: la condonación de intereses y multas}

En la legislación chilena, se establece la condonación de los intereses y multas que se devenguen como consecuencia del incumplimiento o cumplimiento tardío de las obligaciones tributarias. Cabe destacar, que en el Decreto Ley $N^{\circ} 830$ (1974) existen disposiciones destinadas a condonar únicamente los intereses y multas, por lo que puede afirmarse que la obligación de pagar impuestos es totalmente indisponible.

En cuanto a los intereses, el Código Tributario dispone que los Directores Regionales del Servicio de Impuestos Internos están facultados para condonar intereses

“...por la mora en el pago de los impuestos, en los casos expresamente autorizados por la ley..." (Decreto Ley Nº 830, 1974, art. 6, B, no. 4). Los casos en que el legislador autoriza expresamente al Director Regional del Servicio de Impuestos Internos para realizar una condonación de intereses, pueden agruparse en tres causales.

Primero, cuando el contribuyente pruebe "...que ha procedido con antecedentes que hagan excusable la omisión en que hubiere incurrido" (Decreto Ley N 830, 1974, art. 56, inc. 2); regulados en el artículo del Código Tributario, que dispone:

La condonación parcial o total de intereses penales sólo podrá ser otorgada por el Director Regional cuando, resultando impuestos adeudados en virtud de una determinación de oficio practicada por el Servicio, a través de una liquidación, reliquidación o giro, el contribuyente o el responsable del impuesto probare que ha procedido con antecedentes que hagan excusable la omisión en que hubiere incurrido.

Procederá también la condonación de intereses penales cuando, tratándose de impuestos sujetos a declaración, el contribuyente o el responsable de los mismos, voluntariamente, formulare una declaración omitida o presentare una declaración complementaria que arroje mayores impuestos y probare que ha procedido con antecedentes que hagan excusable la omisión en que hubiere incurrido. (Decreto Ley $N^{\circ} 830,1974$, art. 56, inc. 1 y 2)

Segundo, cuando el Servicio incurre en un error; supuesto regulado en el Código Tributario, que dispone: 
Sin embargo, la condonación de intereses o sanciones podrá ser total, si el Servicio incurriere en error al determinar un impuesto o cuando, dichos intereses o sanciones se hubieren originado por causa no imputable al contribuyente. Para rechazar la solicitud de condonación total en estos casos, el Director Regional deberá emitir una resolución en la que fundadamente señale las razones por las que se trata de una causa imputable al contribuyente. (Decreto Ley $N^{\circ} 830,1974$, art. 6, B, no. 4, inc. 3)

Y también "En los casos en que el Servicio incurriere en error al girar un impuesto, el Director Regional deberá condonar totalmente los intereses hasta el último día del mes en que se cursare el giro definitivo". (Decreto Ley N 830, 1974, art. 56 , inc. 3).

Tercero, cuando los intereses se originan por un motivo no atribuible al contribuyente; situación regulada en el Código Tributario, que dispone "El Director Regional podrá condonar la totalidad de los intereses penales que se hubieren originado por causa no imputable al contribuyente" (Decreto Ley $N^{\circ} 830,1974$, art. 56, inc. 4).

En cuanto a las multas, el Código Tributario (Decreto Ley $N^{\circ} 830,1974$ ) establece que el Director Regional del Servicio de Impuestos Internos está facultado para remitirlas, rebajarlas o suspenderlas en tres casos: Primero, que el contribuyente pruebe "...que ha procedido con antecedentes que hagan excusable la acción $u$ omisión en que hubiere incurrido..." (art. 106, inc. 1). Segundo, autodenuncia y colaboración del infractor. (Decreto Ley $N^{\circ} 830,1974$, art. 106, inc. 1). Tercero, ausencia de perjuicio fiscal (Decreto Ley $N^{\circ} 830,1974$, art. 106, inc. 2).

En síntesis, en todas las disposiciones citadas se encuentra presente la idea de que la condonación de intereses y multas de las obligaciones tributarias exige la existencia de una justificación de la morosidad del contribuyente, en términos que su conducta no resulta reprochable o, a lo menos, poco reprochable. Adicionalmente, la Ley Orgánica del Servicio de Impuesto Internos (Decreto con Fuerza de Ley $\mathrm{N}^{\circ} 7$, 1980, art. 9, inc. 3) señala que al Subdirector de Fiscalización y al Director de Grandes Contribuyentes se les entienden conferidas todas las facultades de los Directores Regionales, por lo que debe entenderse que estos pueden condonar intereses y multas que deriven de obligaciones tributarias insolutas, en los mismos términos del Decreto Ley $\mathrm{N}^{\circ} 830$ (1974, arts. 6, B, no. 4 y arts. 56 y 106).

Por último, el Servicio de Impuestos Internos, en su calidad de órgano fiscalizador en materia tributaria, no es la única entidad que puede condonar intereses y multas. También puede hacerlo la Tesorería General de la República en su calidad de órgano recaudador, de conformidad con lo dispuesto en el Decreto Ley Nº 830 (1974, art. 192, inc. 2). 
Amnistías fiscales en Chile: un análisis desde los principios Constitucionales de igualdad...

Atendido el carácter técnico del Derecho tributario, es frecuente que la legislación sea desarrollada a través de normativa administrativa. Esta característica es útil y necesaria, pero encuentra un importante límite en el principio de legalidad tributaria.

\subsubsection{Circular del Servicio de Impuestos Internos $N^{\circ} 42$ (2006) y el caso Johnson's}

La normativa de carácter administrativo, ha desarrollado las disposiciones del Código Tributario (Decreto Ley $\left.\mathrm{N}^{\circ} 830,1974\right)$ con distintas aproximaciones en las últimas dos décadas. Dado que el concepto clave establecido por el legislador es el de "excusabilidad", lo razonable hubiese sido que la normativa administrativa desarrollara este concepto; sin embargo, no lo hace, a la vez que acuña un nuevo concepto igualmente vago: el de "buen contribuyente", sin definir expresamente lo que esto significa. Así, por ejemplo, la Circular del Servicio de Impuestos Internos $N^{\circ} 42$, de 3 de agosto de 2006, simplemente estableció porcentajes máximos de condonación según el tipo de obligación, incentivando el pago por Internet (Circular N42, 2006, II), y excluyendo del procedimiento a contribuyentes con antecedentes querellados por delitos tributarios o que maliciosamente entrababan la fiscalización tributaria, sin exigir ninguna otra justificación adicional por el incumplimiento (Circular N42, 2006, IV).

Bajo la vigencia de la mencionada Circular No 42 (2006) se produjo la condonación tributaria de la empresa Johnson's S. A., que situó el tema en la discusión pública. Dicha empresa, a fines del año 2011, presentó cuatro solicitudes de condonación de intereses y multas a la Dirección de Grandes Contribuyentes del Servicio de Impuestos Internos, sin mencionar las causales que justificaban la petición. El Decreto con Fuerza de Ley $N^{\circ} 7$ (1980) que fija el texto de la ley orgánica del Servicio de Impuestos Internos dispone: "Sin perjuicio de la jurisdicción territorial de los Directores Regionales, la Dirección de Grandes Contribuyentes tendrá competencia sobre todo el territorio nacional y ejercerá jurisdicción sobre los contribuyentes calificados como 'Grandes Contribuyentes' por Resolución del Director, cualquiera fuere su domicilio" (art. 3, inc. 1). De acuerdo con el Informe 234-2012 de la Contraloría General de la República (2013), en la primera y en la segunda oportunidad, el contribuyente solicitó una condonación de intereses y multas por un total de $\$ 54.749 .307 .274$; se concedió una condonación por un total de $\$ 54.400 .378 .383$, es decir, equivalente a más del $99 \%$ de lo solicitado. En la tercera y cuarta oportunidad, el contribuyente solicitó una condonación de intereses y multas por un total de US\$ 9.616.121,13; se concedió una condonación por US\$ 9.519.959,92, es decir, equivalente al 99\% de lo solicitado.

Para tener una real dimensión de los montos condonados, considérese que en el período comprendido entre el 1 de enero de 2011 y el 30 de junio de 2012, la Dirección de Grandes Contribuyentes del Servicio de Impuestos Internos concedió 
condonaciones de intereses y multas por $\$ 100.640 .516 .004$ y US\$20.917.422,58. Por tanto, solo la condonación concedida a este contribuyente equivale al $54 \%$ del total de las condonaciones de intereses y multas concedidas en pesos chilenos, en el grupo de los grandes contribuyentes. Al mismo tiempo, solo la condonación concedida a este contribuyente equivale al $46 \%$ del total de las condonaciones de intereses y multas concedidas en dólares, en el grupo de los grandes contribuyentes.

Este asunto, fue investigado y conocido por una Comisión Investigadora de la Cámara de Diputados. En ella se identificaron evidencias que revelaron un posible conflicto de intereses en el proceso de condonación, dado que el Director del Servicio y el Jefe Jurídico del Servicio de Impuestos Internos, se desempeñaron previamente como directivos en la empresa privada que asesoró a Johnson's en materia tributaria, y que la representó en los litigios que mantuvo durante años con el Servicio de Impuestos Internos. La información suministrada por el mismo Servicio de Impuestos Internos durante la investigación, fue que el peligro de quiebra de la empresa fue determinante en la decisión de condonación (Informe de la Comisión Especial Investigadora, 2012).

A pesar de que no existió una sanción para estos hechos, esta situación refleja la manera cómo se habían venido efectuando las condonaciones de intereses y multas, es decir, a pesar de que la normativa en aquel entonces era bastante precaria, se aprobaron actos administrativos de condonación que la infringían abiertamente y se comienza a cuestionar si estos actos vulneraban los principios constitucionales básicos en materia tributaria. Al mismo tiempo, la crítica de la opinión pública que supuso el caso Johnson's, tuvo como consecuencia un esfuerzo de la administración tributaria por clarificar y objetivar sus criterios.

\subsubsection{Circular del Servicio de Impuestos Internos $N^{\circ} 50$ (2016) y Circular de la Tesorería General de la República N 5 (2016)}

La Ley $N^{\circ} 20.780$ (2014) modificó el artículo 192 inciso $2^{\circ}$ del Código Tributario (Decreto Ley $\left.N^{\circ} 830,1974\right)$, en el sentido de entregar a la propia Tesorería General de la República la obligación de fijar normas o criterios objetivos y de general aplicación que regulen la condonación de los intereses y multas por parte del Tesorero General. Dicha modificación dispone:

Facúltase al Tesorero General para condonar total o parcialmente los intereses y sanciones por la mora en el pago de los impuestos sujetos a la cobranza administrativa y judicial, mediante normas o criterios objetivos y de general aplicación, que se determinarán por dicho Servicio (Ley $\mathrm{N}^{\circ}$ $20.780,2014$, art. 10, no. 34)

Algunos días antes de que entrara en vigor esta obligación, el Servicio de Impuestos Internos y la Tesorería General de la República suscribieron un protocolo donde establecieron las bases para una política de condonación de intereses y mul- 
Amnistías fiscales en Chile: un análisis desde los principios Constitucionales de igualdad...

tas por la mora en el pago de los impuestos, con la finalidad de actuar coordinadamente, fomentar la transparencia de la función pública y respetar la igualdad de los contribuyentes.

El mencionado protocolo, se concretó en la Circular N 50 (2016) del Servicio de Impuesto Internos y en la Circular N 5 (2016) de la Tesorería General de la República. Ambas circulares, tienen por objeto fomentar la eficiencia y eficacia en el cumplimiento de sus funciones; obtener el pronto pago de la deuda aumentando la recaudación fiscal; favorecer al buen contribuyente de manera que la sanción final siempre sea mayor al costo del financiamiento privado. Finalmente, ambos organismos establecen unas tablas con porcentajes máximos de condonación, que varían según la antigüedad de la deuda y según el canal de pago utilizado por el contribuyente, favoreciendo el pago vía Internet, por sobre el pago presencial.

De esta reglamentación, se puede concluir lo siguiente: Primero, la Circular $\mathrm{N}^{\circ}$ 50 (2016) del Servicio de Impuesto Internos intenta definir el concepto de buen contribuyente, señalando que estos son "... aquellos contribuyentes que mantienen, en general, un comportamiento tributario conforme a la ley y reglamentos vigentes" (PG. 4). Segundo, se precisan los márgenes mínimos: a mayor antigüedad se condona un porcentaje menor; si se paga al contado se condona más; si el trámite se realiza por Internet se tiene derecho a acceder a un porcentaje mayor de condonación que si se realiza de forma presencial. Al mismo tiempo, se limitan las condonaciones a los que entraben la fiscalización y los que cometan infracciones sancionadas penalmente.

De acuerdo con lo expuesto, el modelo de condonación de intereses y multas en Chile se puede caracterizar de la siguiente manera:

a) En cuanto a la elegibilidad, es un modelo universal. Si bien se establece como principio general el favorecimiento del "buen contribuyente", con lo que pareciera exigirse una conducta anterior irreprochable en el cumplimiento tributario; en la reglamentación administrativa no se excluye en forma absoluta a contribuyentes que presenten conductas reprochables.

Así, por ejemplo, no se castiga expresamente al contribuyente en situación de reincidencia. Tampoco se establecen diferencias según el tamaño del contribuyente y su capacidad de afrontar las vicisitudes de los ciclos económicos. Por el contrario, existen características que claramente parecen beneficiar a los grandes contribuyentes porque el incentivo al pago al contado de la deuda, contar con una unidad específica del Servicio de Impuestos Internos que resuelve estas solicitudes y el interés recaudatorio del fisco, claramente, los deja en una mejor posición.

b) En cuanto a la cobertura, es una medida que cubre parcialmente las sanciones generadas por el pago moroso de las obligaciones tributarias. Concretamente, hasta un máximo de un $70 \%$ de los intereses y multas.

c) En cuanto a los incentivos, es un modelo que otorga importantes beneficios a los contribuyentes. Si la deuda no tiene más de 3 meses de antigüedad, se paga 
al contado y a través de Internet, permite condonar el $70 \%$ de los intereses y multas. Tampoco existe ninguna obligación ulterior para el contribuyente al que se le concede el beneficio.

d) En cuanto a la duración, es una amnistía fiscal permanente. La consecuencia relevante de esta característica es que los modelos permanentes tienden a fomentar el incumplimiento como técnica de planificación tributaria (Andreoni, 1991, pp. 143-159).

Por estas razones, es posible afirmar que el modelo de condonación de intereses y multas tributarias en Chile es una amnistía fiscal que trata de manera muy beneficiosa al incumplidor regular, que no exige excepcionalidad y que tolera la planificación tributaria agresiva en orden a que los contribuyentes, sobre todo los más grandes, obtengan un provecho de esta circunstancia. Una política tributaria de estas características, si bien no afecta la regulación de los tipos impositivos, pone en riesgo principios constitucionales y legales que dicen relación con la igual aplicación del derecho tributario a todos los contribuyentes. En concreto, como analizaremos más adelante, los principios que pueden verse afectados son el principio de igualdad y el principio de legalidad tributarias.

\subsection{Amnistía fiscal transitoria en Chile: repatriación de capitales}

La Ley N² 20.780 (2014, art. vigesimocuarto transitorio), estableció una institución conocida como la repatriación de capitales. Además, fue reglamentada por la Circular $\mathrm{N}^{\circ} 8$ del Servicio de Impuestos Internos, de 16 de enero 2015.

Se trata de un régimen "...voluntario de declaración de bienes o rentas que se encuentren en el extranjero..." (Ley No 20.780, 2014, art. vigesimocuarto transitorio, inc. 1) en virtud del cual los contribuyentes domiciliados, residentes, establecidos o constituidos en Chile con anterioridad al 1 de enero de 2014, pudieron "...optar voluntariamente por declarar ante el Servicio de Impuestos Internos [...] sus bienes y rentas que se encuentren en el extranjero, cuando habiendo estado afectos a impuestos en el país, no hayan sido oportunamente declarados y/o gravados con los tributos correspondientes en Chile..." (Ley N²20.780, 2014, art. vigesimocuarto transitorio, no. 1).

El régimen estableció “...un impuesto único y sustitutivo de los demás impuestos que pudieren haber afectado a los bienes o rentas declarados, [...] con una tasa de $8 \%$ sobre el valor de dichos bienes o rentas determinado por el contribuyente" (Ley N² 20.780, 2014, art. vigesimocuarto transitorio, no. 8). El régimen es extraordinario y su vigencia fue desde el 1 de enero de 2015 hasta el 31 de diciembre del mismo año.

Con fecha 4 de enero de 2016, el Servicio de Impuestos Internos informó que la aplicación de este régimen implicó recibir "...Un total de 7.832 declaraciones al 31 de diciembre de 2015" (Servicio de Impuestos Internos [SII], 2016a). Este régimen 
permitió recaudar 1.502 millones de dólares. Por tanto, desde el punto de vista de la recaudación a corto plazo, la implementación de esta medida de amnistía fiscal fue considerada exitosa.

De acuerdo con lo expuesto, la amnistía fiscal conocida como repatriación de capitales que rigió en Chile se puede caracterizar de la siguiente manera:

a) En cuanto a la elegibilidad, es un modelo universal. La totalidad de los contribuyentes que se sintiesen motivados por la medida, podían acogerse a esta amnistía fiscal.

b) En cuanto a la cobertura es una medida de cobertura total. Esta medida establece un impuesto único y sustitutivo de cualquier otro impuesto que debió ser aplicado, permitiendo a contribuyentes incumplidores regularizar su situación.

c) En cuanto a los incentivos, es una medida que resulta muy atractiva para los contribuyentes incumplidores, quienes son incitados a regularizar su situación pagando una tasa del $8 \%$, muy inferior a la que debieron haber pagado de acuerdo con el régimen tributario permanente, que en ese entonces era del $20 \%$ para el Impuesto de primera categoría y de hasta un $40 \%$ para el Impuesto global complementario.

d) En cuanto a la duración, es una amnistía fiscal transitoria. Se ofreció como una medida excepcional. Además, la medida fue acompañada del anuncio de que Chile había suscrito el "Acuerdo sobre intercambio de información en materia tributaria" (Organisation for Economic Co-operation and Development [OCDE], 2004), cuyo objetivo es promover la cooperación internacional en materia tributaria y en virtud del cual un grupo de más de 140 países compartiría información financiera y tributaria de sus contribuyentes a partir de 2018. Por tanto, esta medida de amnistía fiscal fue presentada como una buena oportunidad para que los contribuyentes regularizaran su situación tributaria, ante un inminente riesgo de ser fiscalizados y sancionados.

Con todo, poniendo en riesgo la credibilidad de la administración tributaria respecto de la excepcionalidad de esta medida, el Mensaje Presidencial № $107-$ 366, de 23 de agosto de 2018, que inicia el Proyecto de ley que moderniza la legislación tributaria contiene una nueva oportunidad para obtener repatriación de capitales. Se propone un régimen voluntario "... de declaración de rentas y bienes de toda clase (muebles e inmuebles) que se encuentren en el extranjero, sujetos a un impuesto único con tasa de 10\%" (Mensaje Presidencial $N^{\circ} 107-366,2018$, art. transitorio 12). El régimen también sería extraordinario; su duración sería de un año contado desde los dos meses siguientes a la publicación de la ley. Finalmente, esta medida del proyecto de ley que moderniza la legislación tributaria fue rechazada por la Comisión de Hacienda de la Cámara de Diputados. (Sesión Especial, N 122, 2019). La Ley N²1.210, de 24 de febrero de 2020, se aprobó sin incorporar esta nueva medida de repatriación de capitales.

Resulta evidente, que existe una diferencia importante entre el tratamiento de los contribuyentes que pagaron sus obligaciones tributarias sometiéndose al régimen tributario obligatorio y permanente (en aquel entonces, del $20 \%$ para el Impuesto de primera categoría y de hasta un $40 \%$ para el Impuesto global complemen- 
tario), y los contribuyentes que pagaron sus obligaciones tributarias aplicando el régimen tributario voluntario y extraordinario de repatriación de capitales (tributando con una tasa del 8\%). Nuevamente, como analizaremos en los párrafos siguientes, es posible establecer que este tipo de medidas puede afectar principios constitucionales básicos, como el principio de igualdad y el principio de legalidad tributarias.

\section{Análisis desde el Principio Constitucional de Igualdad Tributaria}

Los ordenamientos jurídicos, frecuentemente contienen normas constitucionales que positivizan el deber de contribuir al sostenimiento de los gastos públicos, sujetándolo al cumplimiento de determinados criterios de distribución de la carga tributaria, que suelen denominarse principios constitucionales de Derecho tributario. En este sentido, la Constitución Política de la República de Chile (2005) establece el principio de igualdad tributaria, asegurando a todas las personas "La igual repartición de los tributos en proporción a las rentas o en la progresión o forma que fije la ley, y la igual repartición de las demás cargas públicas" (art. 19, no. 20, inc. 1).

Estos principios, constituyen garantías de los contribuyentes porque sirven de justificación para restringir la potestad tributaria del Estado en la creación de leyes tributarias, de normativa administrativa de desarrollo y en la aplicación del Derecho. Sin embargo, la aplicación de un principio requiere, por su carácter de norma jurídica estructuralmente indeterminada, del trabajo de la doctrina y de la jurisprudencia para concretizar su contenido.

De acuerdo con el desarrollo de la dogmática tributaria, se entiende que el principio de igualdad tributaria se debe respetar en dos sentidos: igualdad en sentido horizontal e igualdad en sentido vertical, a modo de ejemplo, véase a Ordower (2006) y Martinez (2003). La igualdad en sentido horizontal, implica que contribuyentes con una misma capacidad económica deben ser gravados con una misma carga tributaria. La igualdad en sentido vertical, implica que los contribuyentes con mayor capacidad económica deben ser gravados con cargas tributarias más altas que la de aquellos contribuyentes con menor capacidad económica. Las medidas de amnistía fiscal vulneran el principio de igualdad tributaria en ambos sentidos.

Por una parte, se vulnera el principio de igualdad tributaria en sentido horizontal porque las amnistías fiscales producen como consecuencia que, entre dos contribuyentes con igual capacidad contributiva, al contribuyente que cumple morosamente se le aplica un régimen sancionatorio más beneficioso que al contribuyente que cumple oportunamente.

Consideremos dos contribuyentes con igual capacidad económica, un contribuyente cumplidor y otro incumplidor de sus obligaciones tributarias. En el caso de la condonación de intereses y multas, queda en evidencia que se vulnera el principio 
de igualdad en sentido horizontal, si se pone énfasis en el régimen sancionatorio de ambos contribuyentes. El contribuyente diligente, quien paga su obligación tributaria para evitar las sanciones que de acuerdo con la ley llevaría aparejado su incumplimiento, considera en su decisión un régimen sancionatorio más perjudicial que el que, efectivamente, se aplica al contribuyente moroso beneficiado por la condonación. En el caso de la repatriación de capitales, la vulneración es aún más evidente, porque el régimen de tributación del contribuyente cumplidor, con una tasa del $20 \%$ o del $40 \%$ según el caso, es significativamente superior a la tasa del $8 \%$ con la que tributa el contribuyente incumplidor.

Por otra parte, se vulnera el principio de igualdad tributaria en sentido vertical, porque los datos empíricos de aplicación de las amnistías fiscales demuestran que los contribuyentes con mayor poder económico resultan más beneficiados que los contribuyentes con menor poder económico. En el caso de las condonaciones de intereses y multas esto puede ejemplificarse considerando que, con fecha 7 de noviembre de 2018 -después de la entrada en vigencia de la Circular № 50 (2016) -, el Servicio de Impuestos Internos informó que durante el primer semestre de 2018 condonó intereses y multas a “...133.124 contribuyentes, por un monto total de $\$ 53.304$ millones [...] las condonaciones [...] se tradujeron en el ingreso efectivo a las arcas fiscales de \$191.024 millones..." (Servicio de Impuestos Internos [SII], 2018). El beneficio de las grandes empresas queda en evidencia si se considera que, en términos globales, la política de condonación del primer semestre de 2018 supuso un beneficio promedio de $\$ 400.409$ por contribuyente; en tanto que en el sector de las grandes empresas el beneficio promedio fue de $\$ 6.371 .412$, es decir, más de 15 veces del promedio general por contribuyente. En el caso de la repatriación de capitales, nuevamente, la vulneración es aún más evidente, porque el supuesto de aplicación de esta medida de amnistía fiscal es que se trate de contribuyentes que tengan bienes o rentas en el extranjero, y en los hechos el tipo de contribuyente que satisface esta condición son solo contribuyentes con una alta capacidad económica.

Considerando lo expuesto anteriormente, es posible afirmar que toda política de condonación tributaria entra en tensión con el principio de igualdad en materia tributaria. Esto es así, incluso tratándose de una política fiscal que cumpla con los cuatro criterios mínimos que propusimos anteriormente. Lo importante, es considerar que habrá medidas más lesivas que otras; por tanto, lo relevante es que el sacrificio del que es objeto la igualdad tributaria resulte constitucionalmente tolerable.

Frente a este escenario, será la Administración tributaria quien debe justificar la constitucionalidad de su política. Tradicionalmente, en el Derecho Comparado, la constitucionalidad de este tipo de medidas ha sido analizada a la luz del denominado test de proporcionalidad. Este esquema de razonamiento busca evaluar la constitucionalidad de una medida, sujetándola al cumplimiento de cuatro requisitos copulativos: que responda a fin constitucionalmente legítimo, que sea idónea, necesaria y 
proporcionada en sentido estricto. Si la Administración tributaria no está en condiciones de justificar la constitucionalidad de una medida, por no satisfacer la exigencia de alguno de estos cuatro requisitos, se debe concluir que esta es inconstitucional.

A continuación, someteremos las amnistías fiscales chilenas condonación tributaria y repatriación de capitales al test de proporcionalidad:

En cuanto al fin de ambas medidas de amnistía fiscal, se puede establecer claramente que este es aumentar la recaudación fiscal. Existen dos observaciones que permiten cuestionar que estas medidas respondan a un fin constitucionalmente valioso. La primera, consiste en que la aplicación de estas políticas fiscales supone eximir de una sanción a quien reconoce haber violado la ley; si bien esta circunstancia no implica necesariamente que la política sea inconstitucional, es evidente que deben ofrecerse muy buenas razones para ello. La segunda, la aplicación general y permanente de este tipo de políticas fiscales es contraproducente porque, a largo plazo, puede terminar disminuyendo la recaudación fiscal en la medida en que se transmite un mensaje equivocado acerca del valor de la obligación de pagar impuestos oportunamente.

A modo de ilustración, cabe considerar que, con fecha 22 de agosto de 2016 antes de la entrada en vigencia de la Circular N 50 (2016) - el Servicio de Impuestos Internos informó que durante el primer semestre de 2016 “... condonó multas e intereses [...] a 123.128 contribuyentes, por un monto total de \$41.511 millones" (Servicio de Impuestos Internos [SII], 2016b). Recordemos que -después de la entrada en vigencia de la Circular Nº 50 (2016) - el Servicio de Impuestos Internos informó que durante el primer semestre de 2018 “...condonó multas e intereses por infracciones tributarias o diferencias de impuestos no declarados a 133.124 contribuyentes, por un monto total de $\$ 53.304$ millones" (SII, 2018). Por tanto, en un período de dos años el número de contribuyentes beneficiados con condonaciones tributarias aumentó en un $8,12 \%$, y el monto de lo condonado aumentó en un $28,41 \%$.

En cuanto a la idoneidad de ambas medidas de amnistía fiscal para alcanzar el fin de aumentar la recaudación fiscal, es relevante recordar que en la literatura no está clara la efectividad de este tipo de políticas en términos económicos, especialmente, si se consideran sus efectos a largo plazo. El Servicio de Impuesto Internos, ha hecho un esfuerzo por mostrar que la aplicación de estas medidas ha aumentado la recaudación fiscal y, asumiendo implícitamente la incapacidad de la administración tributaria, afirma que sin estas amnistías fiscales los contribuyentes no hubiesen cumplido con su obligación tributaria.

Con todo, las mismas cifras presentadas por el Servicio de Impuestos Internos, admiten una lectura diferente. Así, por ejemplo, en el primer semestre de 2016 se condonaron intereses y multas por $\$ 41.511 .000 .000$, lo que permitió el ingreso efec- 
tivo a las arcas fiscales de $\$ 160.009 .000 .000$; en tanto que, en el primer semestre de 2018 , las condonaciones ascendieron a un monto total de $\$ 53.304 .000 .000$, lo que posibilitó una recaudación de \$191.024.000.000. Evidentemente, el año 2018 las condonaciones permitieron una recaudación fiscal mayor que el año 2016, pero esta manera de presentar los resultados oculta varios datos que son relevantes. Primero,

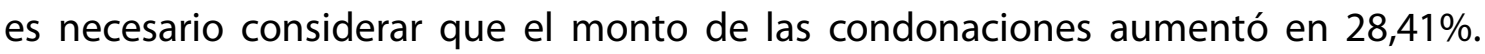
Segundo, si al total de ingresos recaudados se le adiciona el total de ingresos condonados, es posible afirmar que el primer semestre de 2016 el Servicio de Impuestos Internos recaudó el $79,40 \%$ del monto que le correspondía recaudar; dos años después, con la aplicación de la política de condonación tributaria, el Servicio de Impuestos Internos recaudó el 78,18\% del monto que le correspondía recaudar. Por tanto, porcentualmente podría afirmarse que no es efectivo que la aplicación de esta medida haya impactado en los montos efectivamente recaudados ${ }^{2}$. Si, considerando el carácter permanente de esta política, estos resultados se proyectan en el tiempo, podrían mostrar un incremento sistemático del incumplimiento tributario.

En cuanto a la necesidad de ambas medidas de amnistía fiscal, la Administración tributaria está obligada a demostrar que, de todas las medidas que permitan conseguir el fin de aumentar la recaudación fiscal, esta es la medida menos agresiva respecto del principio de igualdad tributaria. La Tesorería General de la República ha justificado la aplicación de los "convenios de pronto pago" (Circular Nº 5, 2016) -que se ofrecen a contribuyentes incumplidores para que concurran, efectivamente, a pagar sus deudas-, argumentando que el hecho de mantener un grupo muy grande de deudas declaradas incobrables resulta aún menos eficiente desde la perspectiva de los fines recaudatorios de todo sistema tributario. Al respecto, es posible promover otras medidas de fiscalización y cobro más eficientes y oportunas que permitan disminuir tal número de deudas declaradas incobrables, sin la afectación a derechos constitucionales. Resulta cuestionable que la medida elegida cumpla con este requisito porque, como se comentó, produce un grave daño a la igualdad tributaria, tanto en sentido horizontal como en sentido vertical.

En cuanto a la proporcionalidad en sentido estricto, la Administración debe demostrar que existe una adecuada relación entre la medida implementada y el fin perseguido, evitando los resultados desmedidos.

El caso Johnson's constituyó una infracción a la ley por lo que, después de dicha experiencia, es valorable el esfuerzo por intentar regular los criterios de aplicación de las condonaciones tributarias. Esto se hizo generalizando el acceso de todos los contribuyentes a este beneficio porque, de lo contrario, las condonaciones serían un privilegio. El problema es que, considerando el daño que esta medida causa al principio de igualdad tributaria, su aplicación debería ser excepcional en cuanto las

\footnotetext{
${ }^{2}$ Es importante considerar que existen diversos factores que pueden afectar a la recaudación, tales como, una política de fiscalización menos efectiva.
} 
causales de procedencia. Por tanto, las medidas de amnistías fiscales deben ser subjetivamente generales en el sentido de que todos los contribuyentes puedan acceder a ellas, pero objetivamente excepcionales en el sentido de que sus causales de procedencia restrinjan al mínimo su aplicación.

En la práctica, las condonaciones de intereses y multas se están aplicando de manera indiscriminada a todo contribuyente, incluso a aquellos que no ofrecen ninguna justificación para su incumplimiento. Esto explica que, al comparar los datos de las condonaciones del primer semestre de 2016 con los del primer semestre de 2018, el efecto ha sido aumentar el número de contribuyentes que solicitan condonaciones y aumentar el monto de lo condonado. En cuanto al número de contribuyentes que solicitan condonaciones, por segmento, el grupo de personas naturales aumentó en un 166,65\%; el grupo de los microempresarios disminuyó en un 4,72\%; el grupo de las pequeñas empresas aumentó en un 6,42\%; el grupo de las medianas empresas aumentó en un 13,71\% y el grupo de las grandes empresas aumentó en un 14,47\%. En cuanto al monto de las condonaciones, por segmento, el grupo de personas naturales aumentó en un 72,25\%; el grupo de los microempresarios disminuyó en un 68,41\%; el grupo de las pequeñas empresas aumentó en un 22,38\%; el grupo de las medianas empresas aumentó en un $96,32 \%$ y el grupo de las grandes empresas aumentó en un 117,05\%. Estos últimos datos evidencian, nuevamente, el daño que se produce al principio de igualdad en sentido vertical al mostrar que los contribuyentes más beneficiados con esta medida son los contribuyentes con mayor poder económico.

Tanto la política de condonación de intereses y multas como la repatriación de capitales son medidas de amnistías fiscales que lesionan gravemente el principio de igualdad tributaria, en sentido horizontal y en sentido vertical ${ }^{3}$. El diseño e implementación de estas medidas no cumple con ninguno de los criterios exigidos y, en consecuencia, no aprueba el test de proporcionalidad exigido a las medidas que lesionan derechos fundamentales. Por tanto, es urgente que su aplicación comience a ser excepcional en cuanto a sus causales de procedencia, manteniendo el mensaje de que en toda sociedad democrática es importante cumplir oportunamente con el deber de contribuir al sostenimiento de los gastos públicos.

\section{Análisis desde el Principio Constitucional de Legalidad Tributaria}

Otro eventual problema es la vulneración del principio de legalidad tributaria. Este principio también se encuentra establecido en la Constitución Política de la República de Chile (2005, art, 19, no. 20), y como explica extensamente Massone Parodi

\footnotetext{
${ }^{3}$ Es importante aclarar que el concepto "aplicación del principio de igualdad tributaria en sentido horizontal" es distinto del concepto "efecto horizontal de los derechos fundamentales" que se ha desarrollado, especialmente, tratándose de las relaciones laborales.
} 
(2016, pp. 134 y ss.), la legalidad de los tributos posee una larga tradición en Chile y en las legislaciones comparadas. En cualquier caso, se debe tener presente que no se trata solo de una particularidad de la regulación tributaria, pues el principio de legalidad es la regla general en el Derecho público chileno en relación con la distribución de competencias de los órganos reguladores. Para poder determinar en qué sentido la política de amnistías fiscales entra en tensión con el principio de legalidad, es necesario establecer algunas consideraciones previas.

El significado básico de este principio consiste en que, en los casos en que la Constitución reserva una materia al legislador, en términos generales, la administración no puede intervenir sustantivamente en su regulación (Bermúdez Soto, 2008). Al efecto, es importante recordar que en Chile la Administración del Estado posee capacidad regulatoria en virtud de la atribución denominada potestad reglamentaria. Esta se encuentra regulada en la Constitución Política de la República de Chile (2005) a propósito del Presidente de la República, distinguiéndose entre potestad reglamentaria autónoma y de ejecución. La primera, comprende una capacidad regulatoria completa, por ende, se sitúa en oposición con la reserva legal (Cazor Aliste, 1999, pp. 75-79). La segunda, implica la posibilidad de desarrollar un estatuto normativo, dentro del marco establecido por la legislación Como expresa Moraga Klenner, "la circunstancia que el Constituyente establezca la reserva de ley [...] no significa que la potestad reglamentaria esté impedida absolutamente de entrar a normar, de un modo colaborativo y particularizador en aspectos instrumentales y con sujeción a la ordenación legal superior, a la propia ley" (citado en Cazor Aliste y Guiloff Titiun, 2011, p. 487)

Además del Presidente de la República, existen otros órganos de la Administración del Estado que poseen capacidad reguladora a través de la potestad reglamentaria. Algunos de ellos por expresa disposición de la Constitución (2005): Banco Central (art. 109, inc. final), Gobiernos Regionales (art. 113, inc. 1) o Municipalidades (art. 119, inc. 2); otros, porque así lo establecen sus respectivos estatutos legales. Tal es el caso de la Dirección del Trabajo, Superintendencias y de los órganos con competencia en materia tributaria y aduanera. Es importante tener presente que solo el Presidente de la República está dotado de la potestad reglamentaria autónoma y el resto de los órganos de la administración, al estar subordinados a la ley, solo pueden ejercer la potestad reglamentaria de ejecución. Para profundizar ver, Ferrada Bórquez (2007).

La relación ley-reglamento históricamente ha sido un tema muy debatido en el Derecho público chileno, incluso desde los tiempos de la Constitución de 1925 (Cea Egaña, 1984, pp. 417-431). En lo que a este artículo concierne, dejaremos fuera los problemas asociados a la potestad reglamentaria autónoma, ya que esta última solo puede operar residualmente en los casos que no son de reserva legal y, según lo dispuesto por la Constitución Política de la República de Chile (2005), son materia de 
ley, e incluso de ley de iniciativa exclusiva del Presidente de la República: "Imponer, suprimir, reducir o condonar tributos de cualquier clase o naturaleza, establecer exenciones o modificar las existentes, y determinar su forma, proporcionalidad o progresión" (art. 65, no. 1). El origen de la potestad reglamentaria de ejecución, se explica en virtud de las mismas características arquitectónicas de la ley. Al respecto, se puede concluir, a partir de la Constitución Política de la República de Chile (2005, art. 63, no. 20), en el Derecho chileno la ley es siempre una norma que posee un carácter general, que establece las bases esenciales de un ordenamiento jurídico (Cordero Quinzacara, 2009). Esta circunstancia es clave para entender el papel de la potestad reglamentaria de ejecución, pues esta permite que las disposiciones generales y abstractas de la ley sean desarrolladas por la norma de origen administrativo, en orden a ser puestas en práctica. Esta relación de colaboración entre ley y potestad reglamentaria de ejecución, adquiere una importancia crucial en áreas altamente tecnificadas como el Derecho tributario. Es por esta razón que, además de la potestad reglamentaria del Presidente de la República, los órganos encargados recaudadores y fiscalizadores también están dotados de la atribución de dictar normas de alcance general para especificar el contenido de las obligaciones tributarias de los contribuyentes.

Sin embargo, en el Derecho chileno esta relación entre ley y potestad reglamentaria siempre ha generado un gran debate. Al respecto, la pregunta a responder es ¿cuáles son esos aspectos instrumentales que la Administración sí puede normar a través de la potestad reglamentaria de ejecución? El asunto no es sencillo, pues como indican Cazor Aliste y Guiloff Titiun (2011):

No existe en la Constitución una respuesta a esa interrogante, por cuanto, como se ha señalado, solo dispone que el Presidente puede dictar reglamentos de ejecución en materia de ley. Interpretando esa norma en armonía con la disposición contenida en el artículo $63 \mathrm{~N}^{\circ} 20$, puede concluirse que no puede considerarse como aspecto instrumental, y por tanto regulable por la vía reglamentaria, el núcleo esencial de la materia sujeta a reserva. (p. 488)

En la práctica, esa cuestión se ha traducido en el debate acerca de si las reservas de la Constitución Política de la República de Chile $(2005$, art. 63) son absolutas o relativas. Que la reserva de ley sea entendida en términos absolutos quiere decir que, cuando la Constitución dispone que una materia sea regulada por el legislador, este debe abordar dicha materia en su integridad, dejando a la Administración únicamente aspectos relativos a su puesta en práctica, por ejemplo, estableciendo plazos para la entrada en vigor de la norma o la logística necesaria para su aplicación. Por el contrario, que una reserva sea relativa significa que el espacio de regulación es compartido entre el legislador y la administración. Obviamente, en este modelo la ley debe abordar los aspectos esenciales de una regulación, pero ello no impide que, respecto 
Amnistías fiscales en Chile: un análisis desde los principios Constitucionales de igualdad...

del contenido específico, la potestad reglamentaria pueda gozar de cierta libertad de configuración normativa, sin contradecir la ley y sin afectar derechos fundamentales.

El asunto ha sido arduamente debatido, estando la doctrina dividida al respecto. Por ejemplo, Fermandois Vöhringer (2001), a comienzos de la década de 2000, criticaba duramente al Tribunal Constitucional, que por entonces comenzaba a ser más deferente con el reglamento de ejecución. En el mismo sentido se manifestó Pierry Arrau (1992, p. 82). En la vereda opuesta, Guiloff Titiun (2012) ha propuesto un modelo que él denomina de legislación no transitiva, que parece descansar en un enfoque similar al de la Ley № 19.300 (1994), de Bases Generales del Medio Ambiente, con amplios márgenes de discrecionalidad regulativa en favor de la Administración del Estado.

El debate en sede jurisprudencial, si bien no exento de polémica, se ha ido uniformando en favor de una tesis ecléctica, que reconoce la existencia de un margen más o menos amplio en favor de la administración, pero sigue considerando a la ley el centro de gravedad del sistema de fuentes del Derecho público. La jurisprudencia constitucional en la década de 1990, sostuvo la tesis de que las reservas del artículo N 63 de la Constitución Política de la República de Chile (2005) son absolutas - véanse al respecto, las siguientes sentencias del Tribunal Constitucional; Requerimiento de un grupo de Diputados respecto del Decreto Supremo del Ministerio de Obras Públicas $N^{\circ} 357$, publicado en el Diario Oficial de 19 de febrero de 1992, que prohibió la colocación de carteles, avisos de propaganda o cualquiera otra forma de anuncios comerciales en los caminos públicos del país (1992); Requerimiento formulado por diversos diputados para que el Tribunal declare la inconstitucionalidad del Decreto Supremo No 327, del Ministerio de Obras Públicas, publicado en el Diario Oficial de 29 de diciembre de 1992, (1993); Requerimiento de un grupo de Diputados y Senadores respecto del Decreto Supremo $N^{\circ} 1^{\circ}$, de 10 de enero de 1996, del Ministerio de Bienes Nacionales, publicado en el Diario Oficial de 6 de agosto del mismo año, (1996)-. No obstante, paulatinamente dicha tesis fue mutando hacia la relativización de la reserva de ley, primero en votos particulares, después en votos de mayoría. A partir de la sentencia Rol N 370-03 (Requerimiento de inconstitucionalidad presentado por un grupo de Senadores respecto del Decreto Supremo No 1, del Ministerio de Vivienda y Urbanismo, publicado en el Diario Oficial de $1^{\circ}$ de febrero de 2003, 2003), la jurisprudencia del Tribunal Constitucional ha reconocido la existencia de cierto espacio de libertad de configuración normativa en favor de la administración, aunque con limitaciones. En síntesis, el Tribunal Constitucional ha sostenido que el art. 63 de la Constitución Política de la República de Chile (2005), por regla general, contempla un espacio de colaboración entre el legislador y la administración. Sin embargo, ello no significa que el legislador pueda simplemente reenviar una materia a la administración, pues se requiere que la disposición legislativa cuente con la suficiente densidad normativa, esto es, con la suficiente determinación y especificidad de sus disposiciones. 
Teniendo lo anterior en cuenta, es necesario distinguir la situación de la política de condonación de intereses y multas respecto de la política de repatriación de capitales. La primera representa el caso más interesante de analizar, mientras que el segundo caso pierde relevancia desde esta óptica, y ello porque la norma legal, la Ley $\mathrm{N}^{\circ} 20.780$ (2014, art. vigesimocuarto transitorio), a simple vista, cumple con las exigencias de densidad normativa que establece el Tribunal Constitucional.

En el caso de la política de condonación de intereses y multas, a su vez, se debe también diferenciar entre ambos supuestos. Para el caso de la condonación de intereses penales, las expresiones utilizadas por el Código Tributario (Decreto Ley $\mathrm{N}^{\circ}$ $830,1974)$ son: "...antecedentes que hagan excusable la omisión..." (art. 56, inc. 1 y 2), "...casos en que el Servicio incurriere en error..." (art. 56, inc. 4) o "...causa no imputable al contribuyente..."(art. 56, inc. 4). La conclusión que se puede obtener para esta hipótesis, es que el ámbito de discrecionalidad de la administración es mínimo. Ambos conceptos poseen un denso y riguroso contenido técnico. Error significa falso concepto o apreciación de la realidad y debe provenir del Servicio de Impuestos Internos, no del contribuyente. Desde la posición de este último, lo que la ley exige para poder acceder a la condonación es que el incumplimiento sea inimputable. Ello quiere decir, que lo que se exige es que el incumplimiento sea producto de caso fortuito o fuerza mayor. Si ello es efectivo, corresponderá al contribuyente acreditar que concurre alguna de estas circunstancias. Todos estos conceptos han sido largamente tratados por la doctrina y la jurisprudencia de los tribunales civiles.

Distinta es la regulación de la condonación de multas. El Código Tributario establece las siguientes causales:

...[1] si el contribuyente probare que ha procedido con antecedentes que hagan excusable la acción u omisión en que hubiere incurrido... [2] si el implicado se ha denunciado y confesado la infracción y sus circunstancias.

...[3] el Director Regional podrá anular las denuncias notificadas por infracciones que no constituyan amenazas para el interés fiscal u omitir los giros de las multas que se apliquen en estos casos, de acuerdo a normas o criterios de general aplicación que fije el Director. (Decreto Ley $\mathrm{N}^{\circ} 830$, 1974, art. 106)

De lo anterior se desprende que, para esta materia, la libertad de configuración normativa que posee la administración es mucho mayor, pues si bien es cierto que la primera causal está redactada en términos semejantes que las que se aplican a las condonaciones de intereses, las dos últimas, son de una extraordinaria amplitud y, en la práctica, terminarán subsumiendo a la primera. De todas formas, conviene analizarlas. Es así como, en el caso de la autodenuncia, simplemente se requiere la comunicación a la autoridad administrativa, la que se debería dar por cumplida con la sola solicitud de condonación de la multa. No obstante, la última hipótesis contie- 
ne un supuesto todavía más general, que es el de anular las denuncias de oficio, sin que medie solicitud del contribuyente infractor. En cualquier caso, para esto último se requiere que se configure el presupuesto habilitante de que la condonación no represente una amenaza para el interés fiscal, pero para ello se deben fijar criterios generales.

Por tanto, las causales no son idénticas para ambos casos. La normativa administrativa, al menos la del Servicio de Impuestos Internos, no puede soslayar esa distinción. Las condonaciones de intereses en la ley son más restrictivas que las de las multas. Esta solución del legislador parece apropiada ya que más allá de que en esta materia los intereses tienen un carácter sancionatorio, en términos originales el objetivo de esta institución es incorporar el costo por el uso alternativo del dinero.

Por su parte, la redacción del artículo 192 del Código Tributario, presenta problemas de densidad normativa que incluso ponen en cuestión su constitucionalidad. Dicha disposición le entrega al Tesorero General la atribución de “...condonar total o parcialmente los intereses y sanciones por la mora en el pago de los impuestos sujetos a la cobranza administrativa y judicial, mediante normas o criterios objetivos y de general aplicación..." (Decreto Ley № 830, 1974, art. 192, inc. 2), que se determinarán por la misma Tesorería (modificación establecida en la Ley $\mathrm{N}^{\circ}$ 20.780, 2014, art. 10, no. 34). En esos términos, este artículo es difícilmente compatible con la Constitución Política de la República de Chile (2005, art. 65, no. 1), pero aun si se concluyese que es constitucional, debería ser dotada de contenido por la regulación administrativa, porque la misma norma así lo establece. En cualquier caso, en esa regulación no pueden ser vulnerados los derechos fundamentales de los contribuyentes ni el ordenamiento jurídico en general, por lo que aquí valga todo lo dicho en la sección tres de este trabajo.

A la luz de todo lo anterior, se puede comprobar que ninguna de las Circulares del Servicio de Impuestos Internos que se han aprobado en la materia cumple con estas exigencias, ni considera las causales que establece la Ley. Por el contrario, pareciera ser que su regulación tiene poca relación con la regulación del Código Tributario (Decreto Ley $\left.N^{\circ} 830,1974\right)$. Por ejemplo, la Circular $N^{\circ} 50$ (2016) establece una causal distinta, el concepto de "buen contribuyente" que, sin perjuicio de que tampoco se detalla claramente su significado, la regulación difiere considerablemente de la establecida en el Código Tributario (Decreto Ley $N^{\circ}$ 830, 1974). Del mismo modo, ninguna de las Circulares establece la distinción entre condonación de intereses y multas, estableciendo todas ellas un estatuto común para ambos supuestos.

Por las razones antes expuestas, la normativa que regula la política de condonación de intereses y multas presenta varios problemas desde el punto de vista del cumplimiento del principio de legalidad, en relación con los requisitos de la Constitución Política de la República de Chile (2005, art. 7) exigidos para considerar válidos 
los actos de los órganos del Estado. Incluso, el Decreto Ley № 830 (1974, art. 192), presenta serias dudas de constitucionalidad. De esta manera, a pesar de que es correcto afirmar que los órganos fiscalizadores y recaudadores en materia tributaria sí están habilitados para regular los procedimientos de condonaciones tributarias, ello se debe entender como un proceso de especificación de la norma legal, que debe operar en los ámbitos de discrecionalidad que el legislador entrega a la administración, pero jamás la regulación administrativa puede contradecir lo dispuesto en la norma legal, ni menos infringir la Constitución.

\section{Conclusiones}

En el presente trabajo, nos planteamos analizar la constitucionalidad de dos medidas de amnistías fiscales implementadas en Chile, una de manera permanente y otra, de manera transitoria. Nos enfocamos, especialmente, en la tensión que producen en relación con el principio de igualdad y el principio de legalidad tributaria. Nuestras conclusiones son las siguientes:

1. El cumplimiento de la obligación tributaria se encuentra protegido jurídicamente. El contribuyente que no cumple completa y oportunamente con la obligación de pagar impuestos, debe pagar su obligación reajustada y es sancionado con el pago de intereses y multas. La fijación de intereses altos, responde a la necesidad de evitar que los contribuyentes dejen de pagar impuestos oportunamente invirtiendo en otras actividades económicas, de manera tal que pudiese resultarles rentable cumplir morosamente con la obligación tributaria. El establecimiento de multas, tiene por objetivo que los contribuyentes perciban que el incumplimiento de las obligaciones tributarias conlleva la imposición de una sanción.

2. Toda política de amnistía fiscal debería cumplir con los cuatro criterios básicos siguientes: (a) Excepcionalidad en la elegibilidad. Las amnistías fiscales deberían aplicarse solo a contribuyentes que, encontrándose en morosidad, no presenten incumplimientos dolosos; de este modo, se busca evitar que las amnistías fiscales sean percibidas como un premio al contribuyente evasor de la ley tributaria. (b) Desincentivo de la reincidencia. Por razones similares al criterio anterior, las amnistías fiscales deberían aplicarse solo a contribuyentes que no sean reincidentes. (c) Prohibición de premio al incumplimiento. Las amnistías fiscales deben establecerse de manera que nunca el contribuyente moroso reciba un tratamiento tributario más beneficioso que el contribuyente que cumple oportunamente; de lo contrario, se emite un mensaje en el sentido de que la evasión es tolerable e insignificante; pudiendo generar graves consecuencias financieras a largo plazo al reducirse el cumplimiento tributario oportuno y voluntario. (d) Principio de reserva legal. Como consecuencia del principio constitucional de legalidad tributaria, los aspectos bási- 
cos de las amnistías fiscales deben estar establecidos por ley, dejando solo los aspectos de detalle a la normativa de carácter administrativo.

3. La política de condonación de intereses y multas tributarias en Chile, es una amnistía fiscal que trata de manera muy beneficiosa al incumplidor regular. Ello, porque no exige excepcionalidad y porque tolera la planificación tributaria agresiva en orden a que los contribuyentes, sobre todo los más grandes, obtengan un provecho de esta circunstancia.

Resulta evidente, que existe una diferencia importante entre el tratamiento de los contribuyentes que pagaron sus obligaciones tributarias sometiéndose al régimen tributario obligatorio y permanente (en aquel entonces, del 20\% para el Impuesto de primera categoría y de hasta un 40\% para el Impuesto global complementario), y los contribuyentes que pagaron sus obligaciones tributarias aplicando el régimen tributario voluntario y extraordinario de repatriación de capitales (tributando con una tasa del 8\%).

4. Tanto la política de condonación de intereses y multas, como la repatriación de capitales, son medidas de amnistías fiscales que lesionan gravemente el principio de igualdad tributaria, en sentido horizontal y en sentido vertical. El diseño e implementación de estas medidas no cumple con ninguno de los criterios exigidos $y$, en consecuencia, no aprueba el test de proporcionalidad exigido a las medidas que lesionan derechos fundamentales. Por tanto, es urgente que su aplicación comience a ser excepcional en cuanto a sus causales de procedencia, manteniendo el mensaje de que en toda sociedad democrática es importante cumplir oportunamente con el deber de contribuir al sostenimiento de los gastos públicos.

5. Respecto del principio de legalidad tributaria, puede estimarse que la norma legal que estableció la repatriación de capitales (Ley N²0.780, 2014, art. vigesimocuarto transitorio), cumple con las exigencias de densidad normativa que establece el Tribunal Constitucional. Al contrario del Decreto Ley $\mathrm{N}^{\circ} 830$ (1974, art. 192), que regula la política de condonación de intereses y multas, entra en tensión con el principio de legalidad en materia tributaria, e incluso produce dudas en torno a su constitucionalidad por una eventual infracción artículo $7^{\circ}$ de la Constitución Política de la República de Chile (2015). De este modo, aunque los órganos fiscalizadores y recaudadores en materia tributaria poseen atribuciones para especificar y ejecutar las disposiciones legales respectivas, dicha potestad reglamentaria debe operar dentro de los ámbitos de discrecionalidad que el legislador entrega a la administración. En ningún caso, dichas normas administrativas pueden contradecir lo dispuesto en normas de rango legal o constitucional. 


\section{Reconocimientos}

Este trabajo forma parte de la investigación llevada a cabo en el proyecto del del Fondo Nacional de Desarrollo Científico y Tecnológico (FONDECYT) de Iniciación №11190344, titulado «Elusión fiscal. Hacia la construcción de una teoría normativa para la interpretación de la norma general antielusiva en el Derecho tributario chileno», cuya investigadora responsable es la Dra. Patricia Toledo Zúñiga.

\section{Referencias Bibliográficas}

Alm, J. (1998). Tax policy analysis: the introduction of a russian tax amnesty. GSU Andrew Young School of Policy Studies, International Studies Program, Working paper $\mathrm{N}^{\circ}$ 98-6. doi: 10.2139/ssrn.471321

Álvarez García, S. (2012). Recaudación tributaria en tiempos de crisis. Las amnistías fiscales. Cuadernos de información económica, 229, 7-11. Recuperado de https://bit.ly/3cmCgSy

Andreoni, J. (1991). The desirability of a permanent tax amnesty. Journal of public economics, 45(2), 143-159. doi: 10.1016/0047-2727(91)90037-3

Armentia Basterra, J. (2015). Amnistía fiscal: ética y legalidad. Zergak (Vitoria. Internet), (50), 79-90. Recuperado de https://bit.ly/2UiKbux

Bermúdez Soto, J. (2008). El principio de legalidad y la nulidad de derecho público en la Constitución Política. Fundamentos para la aplicación de una solución de derecho común. Revista de derecho público, (70), 273-285. Recuperado de https://bit.ly/3AgoWJV

Carvalho, P. D. (1997). Curso de direito tributário (9a ed.). São Paulo, SP: Saraiva.

Cazor Aliste, K. (1999). La potestad reglamentaria autónoma en la Constitución chilena. Revista de derecho (Valdivia), 10(1), 75-79. Recuperado de https://bit.ly/3y5xT6Q

Cazor Aliste, K. y Guiloff Titiun, M. (2011). La reserva de ley y la necesidad de redefinir su función en el Estado constitucional chileno. En J. Couso Salas (Ed.), Anuario de derecho público -2011 (pp. 478-501). Santiago: Ediciones Universidad Diego Portales. Recuperado de https://bit.ly/3vXhNfa

Cea Egaña, J. L. (1984). Dominio legal y reglamentario en la Constitución de 1980. Revista chilena de derecho, 11(2-3), 417-431. Recuperado de https://bit.ly/3vZ5hvC

Circular $\mathrm{N}^{\circ}$ 5. Comunica política de convenios y condonación permanente del Servicio de tesorerías para el pago de los impuestos y créditos fiscales morosos sujetos a 
cobranza por el Servicio de Tesorerías. Tesorería General de la República, Santiago, Chile, 29 de febrero de 2016. Recuperado de https://bit.ly/3wCYwQo

Circular $N^{\circ}$ 8. Imparte instrucciones sobre el sistema de declaración voluntaria y extraordinaria para el pago del impuesto único y sustitutivo establecido en el artículo $24^{\circ}$ transitorio de la Ley $N^{\circ} 20.780$. Servicio de Impuestos Internos, Subdirección Jurídica Departamento de Asesoría Jurídica, Santiago, Chile, 16 de enero de 2015. Recuperado de https://bit.ly/2Sys960

Circular $N^{\circ}$ 42. Establece política de condonación de intereses y sanciones pecuniarias que se impongan por infracciones a las obligaciones tributarias contempladas en el artículo $97 \mathrm{~N}^{\circ} 1$ inciso $1^{\circ}, \mathrm{N}^{\circ} 2$ y $\mathrm{N}^{\circ} 11$ del Código Tributario y condonación en el caso de deudas por concepto de impuesto territorial. Servicio de Impuestos Internos, Santiago, Chile, 3 de agosto de 2006. Recuperado de https://bit.ly/3ylBs9f

Circular $\mathrm{N}^{\circ}$ 50. Establece política de condonación de intereses y sanciones pecuniarias que se impongan por infracciones a las obligaciones tributarias contempladas en el artículo $97 \mathrm{~N}^{\circ} 1$ inciso $1^{\circ}, \mathrm{N}^{\circ} 2$ y $\mathrm{N}^{\circ} 11$ del Código Tributario, condonación de intereses en el caso de deudas por concepto de impuesto territorial, supervisión de la concesión del beneficio y política de transparencia. Servicio de Impuestos Internos, Subdirección de Fiscalización, Santiago, Chile, 20 de julio de 2016. Recuperado de https://bit.ly/2TEnqjQ

Constitución Política de la República de Chile. Diario Oficial de la República de Chile, Santiago, Chile, 22 de septiembre de 2005. Recuperado de http://bcn.cl/1uva9

Contraloría General de la República (2013, Julio 10). Servicio de Impuestos Internos (Informe final no. 234-12). División de Auditoría Administrativa. Recuperado de https://bit.ly/2SwXU03

Cordero Quinzacara, E. (2009). El sentido actual del dominio legal y la potestad reglamentaria. Revista de derecho (Valparaíso), (32), 409-440. doi: 10.4067/s071868512009000100012

Declaración de inaplicabilidad por inconstitucionalidad. AFP Provida con Club de Deportes Santiago Wanderers, Rol N²537-13 (Tribunal Constitucional 9 de octubre de 2014). Recuperado de https://bit.ly/3zAAtDt

Declaración de inaplicabilidad por inconstitucionalidad. AFP Santa María con Club de Deportes Santiago Wanderers, Rol № 2536-13 (Tribunal Constitucional 9 de octubre de 2014). Recuperado de https://bit.ly/3iNnoRy

Declaración de inaplicabilidad por inconstitucionalidad. Comercial Único Limitada con Servicio de Impuestos Internos, Rol N² 2489-13 (Tribunal Constitucional 15 abril de 2014). Recuperado de https://bit.ly/3ilPhdn 
Decreto con Fuerza de Ley $N^{\circ} 7$. Fija texto de la Ley Orgánica del Servicio de Impuestos Internos y adecua disposiciones legales que señala. Diario Oficial de la República de Chile, Santiago, Chile, 15 de octubre de 1980. Recuperado de http://bcn.cl/2k1bj

Decreto Ley N 830. Código Tributario. Diario Oficial de la República de Chile, Santiago, Chile, 31 de diciembre de 1974. Recuperado de http://bcn.cl/2f75t

Fermandois Vöhringer, A. (2001). La reserva legal: una garantía sustantiva que desaparece. Revista chilena de derecho, 28(2), 287-298. Recuperado de https://bit.ly/3uWrHwd

Ferrada Bórquez, J. C. (2007). Las potestades y privilegios de la administración pública en el régimen administrativo chileno. Revista de derecho (Valdivia), 20(2), 69-94. doi: $10.4067 /$ s0718-09502007000200004

Giuliani Fonrouge, C. M. (1970). Derecho financiero (2a ed.). Buenos Aires: Depalma.

Guiloff Titiun, M. (2012). Operativizando la relación ley-reglamento: Una propuesta de redefinición del rol de la reserva legal. Revista de derecho (Valdivia), 25(1), 127-147. doi: 10.4067/s0718-09502012000100006

Informe de la Comisión Especial Investigadora encargada de fiscalizar el comportamiento de los grandes contribuyentes, y las condonaciones efectuadas por el Servicio de Impuestos Internos en los últimos años. Cámara de Diputados, Valparaíso, Chile, 5 de noviembre de 2012. Recuperado de https://bit.ly/3w7XHOC

Jackson, I. A. (1986). Amnesty and creative tax administration. National tax journal, 39(3), 317-323. doi: 10.1086/NTJ41792193

Kellner, M. (2004). Tax amnesty 2004/2005 - An appropriate revenue tool? German law journal, 5(4), 339-346. doi: 10.1017/s2071832200012499

Kelsen, H. (1982). Teoría pura del derecho (2a ed.) (R. J. Vernengo, Trad.). Ciudad de México: UNAM.

Lerman, A. H. (1986). Tax amnesty: The federal perspective. National tax journal, 39(3), 325-332. doi: 10.1086/ntj41792194

Ley $\mathrm{N}^{\circ}$ 19.300. Aprueba ley sobre bases generales del medio ambiente. Diario Oficial de la República de Chile, Santiago, Chile, 09 de marzo de 1994. Recuperado de http://bcn.cl/2f707

Ley $\mathrm{N}^{\circ}$ 20.780. Reforma tributaria que modifica el sistema de tributación de la renta e introduce diversos ajustes en el sistema tributario, Diario Oficial de la República de Chile, Santiago, Chile, 29 de septiembre de 2014. Recuperado de http://bcn.cl/2fa17 
Amnistías fiscales en Chile: un análisis desde los principios Constitucionales de igualdad...

Ley $\mathrm{N}^{\circ}$ 21.210. Moderniza la legislación tributaria. Diario Oficial de la República de Chile, Santiago, Chile, 24 de febrero de 2020. Recuperado de http://bcn.cl/2f9fr

López Laborda, J., y Rodrigo Sauco, F. (2002). El análisis económico de las amnistías fiscales: ¿Qué hemos aprendido hasta ahora? Hacienda pública española, 163(4), 121 156. Recuperado de https://bit.ly/34VBPKU

Martinez, L. P. (2004). The trouble with taxes: Fairness, tax policy, and the constitution. Hastings constitutional law quarterly, 31(4), 413-446. Recuperado de https://bit.ly/3fZiGhL

Massone Parodi, P. P. (2016). Principios de derecho tributario (4a ed.). Santiago: Thomson Reuters.

Mensaje $N^{\circ} 107-366$. Mensaje de S.E. el Presidente de la República con el que inicia el proyecto de ley que moderniza la legislación tributaria. Santiago, 23 de agosto de 2018. Recuperado de https://bit.ly/3dlvYNP

Ministerio de Hacienda. (2017). Estadísticas de las finanzas públicas 2007-2016. Santiago: Ministerio de Hacienda. Recuperado de https://bit.ly/3wZmQvC

Nino, C. S. (2003). Introducción al análisis del derecho (2a ed.). Buenos Aires: Astrea.

Organisation for Economic Co-operation and Development. (2015). Update on voluntary disclosure programmes: a pathway to tax compliance (2a ed.) [PDF]. Recuperado de https://bit.ly/3gySw4o

Organisation for Economic Co-operation and Development. (2004). Acuerdo sobre intercambio de información en materia tributaria. [PDF]. Recuperado de https://bit.ly/2SHMBSH

Ordower, H. (2006). Horizontal and vertical equity in taxation as constitutional principles: Germany and the United States contrasted. Florida tax review, 7(5), 259-334. Recuperado de https://bit.ly/2TrT30C

Patón García, G. (2013). La articulación de técnicas convencionales en los modelos de control tributario y su adecuación a los principios constitucionales: (Una perspectiva desde el ordenamiento español). Direito e desenvolvimento, 4(8), 115-161. doi: 10.26843/direitoedesenvolvimento.v4i8.236

Pérez Rodrigo, A. (2017). Manual de código tributario (10a ed.). Santiago: Thomson Reuters.

Pierry Arrau, P. (1992). El ámbito de la ley. En P. Ibáñez Ojeda, L. F. Luengo Escalona, M. Otero Lathrop, T. P. Elorza, P. Pierry Arrau, J. T. Valdés, ... A. Zaldívar Larraín (Autores), El proceso legislativo en Chile. Seminario 11 y 12 de enero de 1990 (pp. 67-88). Valparaíso: Universidad Católica de Valparaíso. 
Recurso de inconstitucionalidad. Diputados del Grupo Parlamentario Socialista en el Congreso de los Diputados contra la disposición adicional primera del Real Decretoley 12/2012, Sentencia 73/2017 (Tribunal Constitucional de España 8 de junio de 2017). Recuperado de https://bit.ly/3vrcL9C

Requerimiento de inaplicabilidad por inconstitucionalidad. Ilustre Municipalidad de Maipú con Servicio de Impuestos Internos, Rol N³440-17 (Tribunal Constitucional 25 de octubre de 2018). Recuperado de https://bit.ly/3xwDKCb

Requerimiento de inconstitucionalidad presentado por un grupo de Senadores respecto del Decreto Supremo No 1, del Ministerio de Vivienda y Urbanismo, publicado en el Diario Oficial de $1^{\circ}$ de febrero de 2003, Rol N 370-03 (Tribunal Constitucional 9 de abril de 2003). Recuperado de https://bit.ly/3qdEQAp

Requerimiento de un grupo de Diputados respecto del Decreto Supremo del Ministerio de Obras Públicas N 357, publicado en el Diario Oficial de 19 de febrero de 1992, que prohibió la colocación de carteles, avisos de propaganda o cualquiera otra forma de anuncios comerciales en los caminos públicos del país, Rol N 146-92 (Tribunal Constitucional 21 de abril de 1992). Recuperado de https://bit.ly/3wzFB9d

Requerimiento de un grupo de Diputados y Senadores respecto del Decreto Supremo No 10, de 10 de enero de 1996, del Ministerio de Bienes Nacionales, publicado en el Diario Oficial de 6 de agosto del mismo año, Rol N²45-96 (Tribunal Constitucional 2 de diciembre de 1996). Recuperado de https://bit.ly/3cNzLcm

Requerimiento formulado por diversos diputados para que el Tribunal declare la inconstitucionalidad del Decreto Supremo № 327, del Ministerio de Obras Públicas, publicado en el Diario Oficial de 29 de diciembre de 1992, Rol N 167-93 (Tribunal Constitucional 6 de abril de 1993). Recuperado de https://bit.ly/3gwOVF3

Servicio de Impuestos Internos. (2016a, Enero 04). SII recibió 7.832 declaraciones voluntarias de capitales en el exterior. Recuperado de https://bit.ly/3cMls6V

Servicio de Impuestos Internos. (2016b, Agosto 22). SIl condonó multas e intereses a más de 123 mil contribuyentes, el $91 \%$ de ellos microempresas y pymes. Recuperado de https://bit.ly/3iTSOR4

Servicio de Impuestos Internos. (2018, Noviembre 07). SII condonó multas e intereses a más de 133 mil contribuyentes, el $85,2 \%$ de ellos microempresas y pymes. Recuperado de https://bit.ly/3cKIMmq

Sesión Especial $N^{\circ} 122$. Comisión de Hacienda, correspondiente al período legislativo 2018-2022. Cámara de Diputados, Valparaíso, Chile, 19 de agosto de 2019. Recuperado de https://bit.ly/2Ua8WIW 
Amnistías fiscales en Chile: un análisis desde los principios Constitucionales de igualdad...

Stella, P. (1991). An economic analysis of tax amnesties. Journal of public economics, 46(3), 383-400. doi: 10.1016/0047-2727(91)90013-r

\section{Para citar este artículo bajo Norma APA 6a ed.}

Toledo Zúñiga, P. y Paredes Paredes, F. I. (2021). Amnistías fiscales en Chile: un análisis desde los principios Constitucionales de igualdad y legalidad tributarias. Revista de Derecho (Coquimbo. En línea), 28, e3816. https://doi.org/10.22199/issn.0718-97532021-0017

Copyright del articulo: @2021 Patricia Toledo y Felipe Paredes

Este es un artículo de acceso abierto, bajo licencia Creative Commons BY 4.0. 